\title{
Get a room: the role of classroom space in sustained implementation of studio style instruction
}

\author{
Alexis V. Knaub ${ }^{*}$, Kathleen T. Foote ${ }^{2}$, Charles Henderson ${ }^{1}$, Melissa Dancy ${ }^{3}$ and Robert J. Beichner ${ }^{4}$
}

\begin{abstract}
Background: The characteristics of the classroom environment play an important role in shaping teaching practices and supporting research-based instructional strategies. One instructional strategy that has reimagined the classroom is the Student-Centered Active Learning Environment with Upside-Down Pedagogies (SCALE-UP). SCALE-UP uses studio-style instruction to facilitate student collaboration. Although there is significant interest in studio-style instruction, there is not much research-based guidance available for institutions interested in setting up a classroom, especially for secondary users interested in using this in different academic settings and contexts. We interviewed key informants involved in 21 successful secondary implementations of SCALE-UP about creating, using, and spreading studio-style classrooms. This paper summarizes respondent's perceptions of (1) how these classrooms are initiated; (2) which classroom features are helpful, non-essential, and unhelpful; (3) how professional development efforts support SCALE-UP instructors; and (4) how the classroom indirectly affects the department and/or institution.
\end{abstract}

Results: Room initiation Interviewees engaged in multiple activities to obtain a studio-style classroom. The majority of interviewees worked in teams created by faculty or administrators, with the participation from both groups. Interviewees typically sought institutional funding to develop the rooms.

Classroom features When developing the room, implementers used many key characteristics of the recommended classroom, such as collaborative workspace (e.g., special tables) for students, but they generally did not replicate all of the recommended features. Interviewees had mixed opinions about the importance of classroom technology.

Professional development and support Interviewees noted the importance of professional development for teaching staff (instructors and teaching assistants) new to the SCALE-UP teaching environment.

Indirect effects Beyond direct benefits to the teachers and learners, our interviewees reported that the classrooms had larger impacts including attracting visitors to the institution and encouraging the use of active learning in non-SCALE-UP classes.

Conclusions: There are many paths to successful development of a studio-style classroom. The process can be initiated by faculty or administrators. Classroom designs can vary to suit the local environment as long as they maintain the intent of the space: to support peer collaboration. Beyond improving student outcomes, these classrooms have additional benefits for institutions that include transforming instructor approaches to teaching and symbolizing the institution's commitment to quality teaching.

Keywords: SCALE-UP, Studio-style instruction, Classroom design, Modifying education innovation, Active learning spaces

\footnotetext{
*Correspondence: avknaub@gmail.com

'Department of Physics, Western Michigan University, 1903 West Michigan

Ave, Michigan 49008, USA

Full list of author information is available at the end of the article
} 


\section{Background}

Teaching practices are affected by the characteristics of both the individual instructor (i.e., beliefs, experience, desires, etc.) and the environment (i.e., physical space, local culture, and available resources) (Beggs 2000; Martin 2002; Cotner et al. 2013). Therefore, the design of the physical classroom space plays an important role in shaping the learning environment. From seating configuration to furniture to technology, the classroom and its features can encourage or discourage particular activities. For example, seating bolted to the floor facing forward toward a projection screen encourages instructor presentations, while round tables with no discernable front of the classroom facilitate group work. Developing non-traditional classroom space can support many active learning instructional strategies that have been shown to produce high student learning (Beichner et al. 2007; Dori et al. 2007; Walker et al. 2011; Narum 2013; Cotner et al. 2013).

Creating such classroom space is not a trivial undertaking, and there is little guidance available for those interested in building non-traditional classroom space. We conducted an interview study of 21 successful initiations of Student-Centered Active Learning Environment with Upside-Down Pedagogies (SCALE-UP), a well-tested instructional reform that radically re-envisions pedagogy and the instructional space (Beichner et al. 2007). SCALEUP is a studio-style reform primarily used in higher education STEM settings, although instructors in other disciplines have implemented SCALE-UP (Foote et al. 2014).

The goal of this study is to better understand how secondary implementers, those who are not the initial developer but adopt the innovation, created successful and sustainable SCALE-UP classrooms. We provide practical advice for those seeking to create a SCALE-UP classroom as well as explore wider implications for other structural reforms. Specific research questions are discussed later in this paper.

What is SCALE-UP and how does it relate to this study? Robert Beichner developed SCALE-UP in 1995 at North Carolina State University (NCSU) as an affordable way to bring the benefits of studio-style instruction to his large enrollment introductory physics classes (Narum 2013). SCALE-UP is an example of a broader class of studio-style reforms (Beichner et al. 2007). Studiostyle teaching combines lecture and lab into one class, frequently incorporating collaborative active learning activities to engage students (Beichner 2014). While students are working on activities, the instructor moves around the classroom to interact with and encourage interaction among students. Other studio-style reforms include workshop physics and studio physics at Renneselaer Polytechnic Institute (Beichner 2014).
The SCALE-UP classroom features special tables, whiteboards, and technology to facilitate collaborative and hands-on learning. It represents a radical departure from a typical lecture hall. The SCALE-UP room design evolved through both experience and research (Beichner et al. 2007). NCSU's current SCALE-UP room is designed for 99 students and has 7 -ft-diameter round tables that each can accommodate three groups of three students (Beichner et al. 2007; Narum 2013). The 7-ft-diameter tables allow students to have enough space for activities and also communicate across the table at a reasonable speaking volume (Beichner et al. 2007). While this table size and shape works well for large classes, other SCALE-UP implementations use other table shapes, for example, Dshaped tables in smaller classes. Instructional technology, such as laptops, and whiteboards are frequently incorporated into the room (Beichner 2014). Laptops are recommended, because they are smaller than desktops and can be stored when not needed (Beichner et al. 2007). Display screens or monitors around the room allow the instructor to show student work to the entire class. Students also use simulations and course software such as WebAssign, an electronic homework and assignment delivery system. Technology can help with course organization (e.g., storing the syllabus online) and promote flexible studentinstructor interaction (e.g., groups submit work online so that instructors can identify and work with groups that need additional assistance).

Why study SCALE-UP?

We chose to study SCALE-UP for the following reasons:

- Demonstrated student success. The results of SCALE-UP style teaching are extremely positive. SCALE-UP has been shown to improve student retention, student problem solving, and success in subsequent courses (Beichner et al. 2007; Dori et al. 2007; Narum 2013). Particularly striking is that the drop, fail, and withdraw (DFW) rates dramatically decrease for women and underrepresented racial minorities and become comparable to nonunderrepresented populations (Beichner 2008).

- Supports development of the twenty-first century skills. While the learning goals vary from instructor to instructor, Beichner (2014) points out that these goals frequently include "twenty-first century skills," which include using technology, working in teams, communicating effectively, and conducting experiments. SCALE-UP classrooms provide an environment where students can practice these skills. National organizations, including the American Institute of Physics (Czujko et al. 2014), the National Academies (Cooke and Hilton 2015), and the White House (President's Council of 
Advisors on Science and Technology 2010) have identified these skills as being valuable for future STEM professionals to develop.

- Widespread usage. A Fall 2013 Survey found that SCALE-UP is used in 114 physics departments, 140 non-physics STEM departments, and 60 nonSTEM (social sciences, arts, business, humanities departments worldwide (Foote et al. 2014). This number has increased as of mid-2015, when 259 colleges and universities have reported their SCALE-UP implementation to Beichner via the SCALE-UP website.

- Requires structural changes. One of the prominent features of SCALE-UP is the redesigned room. A previous study hypothesized that the room may facilitate the spread of SCALE-UP (Foote et al. 2014). Understanding the role of physical changes in education innovation is relevant not only to SCALEUP but also other structural innovations.

As indicated by the widespread usage, SCALE-UP has numerous secondary implementers, faculty, and staff who have adopted the SCALE-UP innovation and created classrooms in their institutions.

Because there are many secondary implementers, fidelity to the original design varies. Although SCALE-UP has recommended room features as described by Beichner (see Table 3 for specific room features), secondary implementers do not always, and are not expected to, strictly adopt the SCALE-UP recommended layout from the NCSU development site. This may be obvious to some readers, but in our experiences, there sometimes are misconceptions that the room design must include all recommended features in order to do SCALE-UP. The SCALE-UP website includes recommendations for different designs (Beichner 2015) based on room size, shape, and class size. Practical constraints, such as current building architecture and costs, also limit what is possible. Beichner (2014) stresses maximizing studentstudent interactions, and fulfilling the learning goals of the instructor should be primary considerations when developing a SCALE-UP classroom.

\section{Lack of SCALE-UP abandoners speaks to the significance} of the room

This paper is a part of a larger study on SCALE-UP secondary implementation. Our initial intent was to study both successful and unsuccessful (i.e., abandoned) implementations of SCALE-UP, defining abandoned SCALE-UP users as those who had modified a classroom but then no longer used the room and were not likely to do so in the future. Those who had considered SCALE-UP but did not create a classroom were not included, as they did not implement the innovation.
In our initial survey which was used to identify the sample reported on in this paper, no clear abandoners were identified. We then set out to find them by posting on LISTSERVs such as PHYSLrnr and PHYS-L, asking for information on abandoned implementations either through direct involvement or through rumor. In the end, we received ten emails that identified ten possible abandoners. We were only able to identify one site that had once implemented SCALE-UP with a redesigned room that is no longer doing SCALE-UP and did not foresee doing it again in the near future, along with one site that abandoned SCALE-UP but would consider trying again. The site that considered revisiting SCALE-UP in the future had one semester where students were enthusiastic toward it and another semester where they were not, resulting in poor grades and low instructor evaluations. The one genuine abandoner has several possibilities why they abandoned it including the lack of departmental buy-in, the room located in a building that was infrequently used by other faculty in the department, and that SCALE-UP was not significantly different enough from current teaching practices to justify the logistical challenges entailing equipment.

This is indicative that if a SCALE-UP implementation can get as far as having an appropriately designed classroom space, there is an excellent chance it will be sustained. In contrast, Henderson et al. (2012) found in a survey of USA physics faculty that approximately one third of faculty who report tying a research-based instructional strategy in general abandon it. The significance of the room to SCALE-UP is why it is the focus of this paper. We want to explore not only the process of secondary SCALE-UP implementation but also what specifically about the room makes SCALE-UP implementation sustained.

\section{Implementation of educational innovations}

SCALE-UP reforms both the classroom space and pedagogy. In order for any innovation, SCALE-UP or otherwise, to be implemented successfully, the organizational climate should be supportive of the implementation (Klein and Sorra 1996; Zhu and Engels 2013). Collaborative efforts at implementation can lead to more successful adoption than those who attempt to implement an innovation individually (Zhu and Engels 2013). The literature in this section makes two important claims about secondary implementations.

\section{Innovations are typically modified to match local characteristics}

When sites adopt innovations developed at other institutions, they become secondary implementers. Educational innovations are often modified during secondary 
implementations due to both institutional differences and various constraints (Henderson and Dancy 2011). Constraints can include the ability to purchase equipment and modify organizational structures to accommodate the change (Wejnert 2002). Institutional differences mean that secondary adopters may need to make adjustments due to aspects such as class size and student population (Henderson and Dancy 2011). Regardless of institution type, instructors who adopt teaching innovations all face time constraints that hinder use (Henderson et al. 2012). With the diversity among SCALE-UP adopters, institutional differences may impact what each implementation looks like.

\section{Training and other teaching support can ease implementation difficulties}

There are significant challenges involved in making instructional changes. Some of these challenges can be minimized through training and support. For example, providing an archive of previous course materials is useful for subsequent instructors (Chasteen et al. 2011). However, simply handing over materials is rarely sufficient; instructors generally need more support (Chasteen et al. 2011).

Workshops on educational innovations can expose instructors to research-based instructional strategies and provide motivation to try these strategies (Frank et al. 2004; Henderson et al. 2012). However, in addition to providing exposure to an innovation, workshops should provide advice to help adopters overcome challenges they are likely to encounter during implementation (Henderson and Dancy 2007). One example of thorough training is at the University of Iowa. Based on faculty feedback, Florman (2014) developed comprehensive training to cover various topics in-depth, such as course transformation and technology use.

Part of this study describes how secondary sites provide training and other support and the perceived impact of that. Although the room is an important piece of implementing SCALE-UP, past studies have shown that learning gains will not increase unless the pedagogy changes to include the interactivity that the room was designed to facilitate (Cummings et al. 1999; Rogers et al. 2015). Providing training is one way to help instructors change their teaching and promote successful implementation.

\section{Room design literature}

Both K-12 and higher education research has examined issues surrounding classroom design. Although the context is different, some of the findings in the K-12 literature apply to higher education. This section provides an overview of the classroom design literature relevant to this study.

\section{Classroom layout can impact teaching practices}

Literature suggests that the physical classroom space has a critical role in changing teaching practice and subsequently, can affect, student learning (Martin 2002; Taylor 2009; Brooks 2011). For example, seating where students face one another, such as U-shape or circular configuration, more readily allows for class discussions (Rosenfield et al. 1985; Bonus and Riordan 1998), clustered desks facilitate cooperative group activities (Bonus and Riordan 1998), and classrooms where students are seated in rows result in higher levels of instructor presentation and direction (Martin 2002).

Active learning environments include strategic seating arrangements. These classrooms often include special tables to promote face-to-face interaction, as well as whiteboards, and computers. These tools can facilitate collaborative learning, help foster student-teacher relationships, and allow students to take ownership of their learning (Taylor 2009; Whiteside et al. 2009; Harvey and Kenyon 2013).

The research literature on active learning environments documents positive impacts of these spaces on attitudes and performance. Students frequently enjoy these spaces in comparison to traditional classrooms (Whiteside et al. 2009; Walker et al. 2011). Students perform better in active learning classrooms over traditional classrooms, even when controlling for factors such as ACT scores and instructor use of active learning methods (Walker et al. 2011; Cotner et al. 2013; Keiner and Gilman 2015). In other words, using active learning instructional strategies in a classroom designed for active learning is more effective than trying to use active learning in a traditional classroom designed for instructor presentation.

Some classroom designs pose challenges for activities such as test taking. Clustered desks, for example, allow for group work but would not be ideal for test taking. However, this challenge can be overcome by using temporary partitions during test time (Rogers et al. 2015). We wanted to collect information like this about challenges that secondary adopters encounter and share potential solutions.

Active learning environments are not standardized, so room characteristics and thus, their impacts, can vary. There have been efforts to create an active learning certification system similar to the LEED green building certification so implementers can understand how well their classrooms facilitate active learning (Felix and Brown 2011). The existing certification described by Felix and Brown, however, is mostly conceptual or based on action, e.g., students and instructors are able to easily interact. In this study, we hope to identify specific room elements that are helpful and unhelpful so secondary implementers who may have budget or other restrictions can prioritize their renovations. 
Although the classroom layout impacts teaching practices, the instructor must be aware of the goals in their lessons and understand how the classroom design supports or hinders these goals when they set up their classrooms (Bonus and Riordan 1998; Lippman 2010). In other words, the instructor needs to know how to use the classroom. One area we were interested in exploring is how instructors learn to teach in an active learning classroom.

\section{Technology is often not used to its fullest extent}

Implementing technological innovations is often challenging. Even when technology is readily available, teachers may opt not to use it or use it in ways that do not make full use of its potential (Cuban 2001). For example, clicker technology can be used as formative feedback so the instructor can modify the lesson plan to address difficulties in real time. However, clickers are often not used in this way and instead used as a way to take attendance or give quizzes. Multiple obstacles, such as a lack of time to develop materials suitable for technology use (Cuban 2001) and the possibility of technological failures (e.g., a website that continues to crash) (Cuban 2001; Frank et al. 2004) deter teachers from using technology to its fullest extent. Since technology can be the most expensive items in the SCALE-UP room redesign, it will be important to understand how this technology is used to ensure that the investment is worthwhile.

Technology in higher education courses can be used effectively, although the use is nuanced. Students generally react positively to classroom use of laptop computers that allow for easier collaboration and channels for feedback (Barak et al. 2006). However, computer usage should be done judiciously. Instructors must recognize the limitation of technological capabilities (Lippman 2010) which can also negatively impact learning. For example, some students find laptop usage distracting and may engage in unrelated online activities (Barak et al. 2006).

Instructor decision-making about using technology is complex. Although administrators may be supportive and provide technology, instructor use of the technology often varies (Cuban 2001). Lasry et al. (2014) found that only about half of the instructors changed their teaching methods when placed in a redesigned classroom configured with technology. Instructors must see value in technology use for student learning in order for it to be adopted (Beggs 2000; Samarawickrema and Stacey 2007). Similar to adopting other educational innovations, instructors have competing responsibilities that take precedent over learning to use technology effectively (Cuban 2001). Instructors may not be willing to invest the time needed to learn the technology or to develop new materials that are compatible with the technology. Training or hiring a technology specialist can ease these burdens (Beggs 2000).
In the SCALE-UP classroom implementation context, the benefits of technology alongside the challenges should be better understood in order to support secondary implementation, especially since technology can be an expensive part of renovation.

\section{Summary}

For the adoption of innovation to be successful, there should be support for those who will be using the innovation. Specific to structural educational innovations, we see that the classroom makes a difference in how instructors teach and students learn, but instructors must change their teaching in order to use the classroom's capabilities effectively. Research suggests that redesigning the classroom can help facilitate more effective interactive instruction if instructors are willing to change practice accordingly.

Research also suggests that instructors can underutilize sophisticated technology that often accompanies active learning classrooms. Similar to the general research on innovation adoption, instructors need assistance and time to develop materials suitable for technology use. These findings are relevant to SCALE-UP, as the radical overhaul of the room design suggests the need for professional development to support effective use.

\section{Current research gap}

The current body of research has some important gaps that this study addresses. By studying 21 secondary implementations of SCALE-UP, we are able to provide an in-depth look at specific aspects related to classroom design. For example, as discussed above, secondary implementers typically modify innovations due to their institutional setting and situational constraints. We will identify whether secondary implementers share similarities in their use of the rooms and typical modifications.

This study also looks at the support provided to instructors to help them use the redesigned classroom successfully. Although the relationship between the classroom environment and instructional practices is discussed in the literature, there is no mention of whether and how instructors receive professional development or other forms of support to use active learning or innovative spaces. This will help adopters know how to support the faculty that teach in these room and, hopefully, increase the likelihood of success.

Lastly, we wanted to see if classrooms have furtherreaching effects on the institution and instructional practices in non-redesigned classrooms. This area is largely unexplored in prior literature.

\section{Research questions}

As mentioned previously, our main research goal is to better understand how secondary sites implement radically 
redesigned classrooms and support instructor use of student-centered pedagogy in these rooms. We believe this is an essential question to be asked by anyone interested in educational reform as the design of the classroom highly influences the nature of what occurs in the classroom.

Our research questions delve into descriptive aspects as well as outcomes associated with the room in order to provide recommendations to anyone interested in creating and using an active learning classroom. This study is also relevant for those interested in initiating radical, structural reforms in general.

1. How was the classroom space initiated?

(a) Who was involved in the classroom space initiation?

(b)Do initial teams have any subsequent impact on SCALE-UP spread?

(c) How was the room financed?

2. What are the characteristics of the classroom space?

(a) How did the implemented classroom characteristics compare to the recommended classroom characteristics?

(b)What characteristics were considered helpful? Non-essential? Unhelpful?

(c) Were additional classrooms built? If so, did subsequent classrooms differ from the initial model?

3. What training or support was offered to instructors who teach in the redesigned classroom space?

(a) What kinds of support or training are provided?

(b)Did implementers need to modify subsequent support and training from their initial implementation at the institution?

4. What indirect effects did the new classroom space have at the institution?

\section{Methods}

The interview participants for this study were identified from the respondents of a previous SCALE-UP-related survey that created a census of instructors who were using SCALE-UP or similar studio-style instructional strategies (Foote et al. 2014). The survey was administered between December 2012 and August 2013 and included questions about how respondents learned about SCALE-UP, room features, longevity of SCALE-UP usage, and interactions with others related to SCALE-UP. We received 659 responses out of approximately 1300 invitations sent. More information about the survey can be found elsewhere (Foote et al. 2014; Neumeyer et al. 2014).

\section{Sample}

We used survey responses to select "successful" implementations of SCALE-UP to study. For our purposes, we defined a successful SCALE-UP implementation as meeting at least one of the following requirements:

1. Multiple departments in a single institution were using SCALE-UP (i.e., high penetration within an institution).

2. Over $60 \%$ of introductory classes in a department were taught using a SCALE-UP style pedagogy (i.e., high penetration within a department).

3. The implementation had been in place for six or more years (i.e., high longevity).

4. Interview participants were named as a source of information by many other survey participants (i.e., high degree centrality in the social network of SCALE-UP dissemination) (Neumeyer et al. 2014).

Only US-based institutions were selected in order to ensure cultural uniformity.

Additionally, a site was only considered to be a true SCALE-UP implementer if they reported the existence of a specialized room with tables to facilitate group learning. We contacted interviewees who survey respondents identified as "key contacts" about the SCALE-UP reform effort.

We contacted 63 key informants based on our criteria above, and 31 agreed to be interviewed. Five pilot interviews were used to refine the interview protocol. We eliminated five interviews because the conversation revealed the implementation did not meet our selection criteria. Our final interview sample used for analysis consisted of 21 faculty, administrators, and staff who were heavily involved with 21 unique SCALE-UP implementations. They represent 19 institutions, with two institutions having two departmental implementations that occurred independent of each other. Institutions are referred by a letter name (e.g., institution A). If two people are interviewed from the institution, they are referred to with an additional number (e.g., institution A-1).

Our sample consisted of 12 doctoral/research institutions, 6 master's colleges and universities, and 1 associate college (Carnegie Classifications 2010). Using the US Census regions, these institutions lie in the northeast $(N=3)$, south $(N=7)$, midwest $(N=5)$, and west $(N=4)$. Thirteen institutions are public, 5 private, and 1 is a community college. In this study, the interviewees discussed implementations in the following departments:

- 10 physics departments

- 3 biology departments

- 2 math departments

- 2 chemistry departments

- 2 engineering departments

- 2 multiple departments 
We acknowledge that our sample is not large, and approximately $50 \%$ of our key informants are based in physics departments. For the former limitation, we decided doing comprehensive interviews with fewer secondary implementers would provide more useful data than more interviews with less detail. The strong representation of physics departments is an artifact of studying SCALEUP; the majority of secondary implementers are based in physics departments (Foote et al. 2014). Although this study has its limitations, the findings on how secondary implementers navigate their local settings to implement SCALE-UP do not appear to be unique to these institutions or to physics.

\section{Interview protocol}

Members of the research team (the authors) conducted semi-structured telephone interviews. We asked about room creation process (e.g., availability of funding and who was involved), room characteristics (including the original purpose of the space and usefulness of features), support/training provided, and any additional impact related to SCALE-UP. While we generally used the same interview protocol, the semi-structured nature allowed us to deviate from the protocol when the interviewee brought up an interesting point. To ensure a more uniform process, our interview protocol included multiple potential follow-up questions to explore.

Interviews were audio recorded and transcribed. This paper focuses on the classroom portion of SCALE-UP implementation, including who was involved in creating the room, sources of funding, a general description of the room, useful/not useful/non-essential room features, faculty training on using the room (e.g., professional development workshops), and additional impact of the room.

\section{Analysis}

All members of the research team worked together in an iterative process using a sub-sample of the interviews to develop a coding scheme and template for analysis. Two members of the research team then independently analyzed data using the coding scheme and guiding questions. The coding scheme was based on themes that appear in the literature, from prior research conducted in this study, and from the research team's experience. The guiding questions asked the following:

- Who was involved with obtaining a SCALE-UP room?

- How was the room funded?

- What kind of space was it (e.g., a new classroom, renovated space)?

- What is the classroom like (e.g., furnishings, room geometry, size)?
- What classroom characteristics are particularly helpful?

- What classroom characteristics are particularly unhelpful?

- What is the impact of the room on the institutional environment?

- What resources are available for faculty (e.g., professional development, curriculum support, teaching assistants)?

Emergent categories were developed from the guiding questions. Some categories were more straightforward to develop (e.g., identifying the source of funding), while others required more interpretation (e.g., whether secondary implementers truly worked in a team). These categories were refined throughout the analysis process. Coders examined each other's responses and resolved discrepancies by coming to consensus through discussion of why they interpreted the data the way they did.

Relevant categories will be introduced in the "Results" section as they become important. It is important to note that because this study used semi-structured interviews to identify emergent categories (and not a priori categories specifically asked about in the interview), the absence of an idea from a particular interviewee does not necessarily mean that this idea was not present in their SCALE-UP implementation. The interviewee may have not mentioned the item or identified it as important.

\section{Results}

This section begins with three SCALE-UP implementation stories from different types of institutions to provide some context to the results. These stories were selected because they represent similar circumstances that others in our sample have experienced. We then present the results in order of the research questions. Although some of the key findings may seem obvious, they are still important to acknowledge. SCALE-UP users have not always initially realized these key findings until much later in the process, even those in our sample identified actions and choices that are more significant in retrospect. We hope explicit acknowledgement will highlight their significance to potential secondary implementers.

Institution $B$ is a large (over 50,000 undergraduates) research institution with a doctoral program.

Initiation: The biology department has a long history of valuing biology education, even hiring biologists who specialize in education. The interviewee was a universitylevel administrator who had been a tenured faculty member in institution B's biology department for many years. He felt that the biology department could improve their teaching. At the same time, the university was focusing on improving student retention. The interviewee "got together a faculty committee. We started talking about what 
we could do and decided that the first course of action would be to determine what were the most essential concepts that we wanted students to learn, our students to learn, during intro bio." Around the same time, the interviewee began attending national biology education research meetings. He noticed that educational resources for biology education increased, noting that the Vision and Change report (an influential biology education research report developed by the AAAS and NSF) had come out around this time. Influenced and inspired by this flurry of events, the faculty committee decided to adopt a studio-style approach.

Funding: Importantly, at this time, the university implemented program fees. The biology department applied to receive some of those fees to support the development of a SCALE-UP classroom: "We were asked to submit a proposal that had to be cleared by pretty much everyone at the university, including the students. Since I had been thinking about this stuff, we had a very mature proposal." The funding allowed them to create a classroom and hire an instructional designer.

Characteristics of classroom: For their first implementation, they renovated an unused classroom into a studio space modeled after SCALE-UP. They built an additional classroom after the first classroom was met with positive reactions. The additional classroom can accommodate 96 students and can be partitioned so that the room is split in half with each side having 48 students. The SCALE-UP room accommodates fewer students than a typical course; the large biology classes at institution B typically enroll 200-300 students but can be as large as 450 . There are tables for student groups, computers, and projection screens.

Support for faculty: The implementation efforts included providing significant support to faculty teaching in the redesigned room. Besides an instructional designer hired to help "flip" classrooms, a curriculum specialist was hired to support course redesign, and a recent faculty hire runs professional development for teaching assistants.

Impact: The classroom has generated interest in active learning, both within and outside of the university: "People saw what we were doing with our intro bio and there's a lot of interest in that; there's also a lot of interest in all the community colleges in this state because they follow what we do a lot. I've done presentations to the undergraduate programs people at community colleges across the state."

Institution $F$ is a master's level university with approximately 10,000 undergraduates.

Initiation: The interviewee from institution $\mathrm{F}$ had a background in physics education research and desired to teach in a more interactive fashion. The physics introductory courses had a history of high DFW rates and student complaints. This interviewee and a colleague in the physical sciences department were interested in SCALE-UP and visited NCSU to observe a class and participate in a workshop. The department chair was excited that faculty wanted to improve teaching in the department and gave permission to modify an existing classroom.

Funding: Funding for the first classroom came from dissemination funds from Beichner's NSF grant. The first classroom was created with modest changes: "They were willing to let us take a classroom and basically pull out all of the individual chairs and then put up whiteboards around the room. That's basically what we started with." After their initial classroom was created, more classrooms were needed due to increasing student population in the university. This created opportunities to have more classrooms renovated for SCALE-UP style teaching. These classrooms were funded through various channels: a colleague's overhead funds, department funds, and university funds that were allocated for furniture."

Characteristics of classroom: The classrooms have hexagonal tables, white boards, projectors, and easy access to lab equipment. They have three classrooms of differing sizes, ranging from 36 to 72 students.

Support for faculty: Although no formal training program exists, faculty members unfamiliar with SCALE-UP frequently shadow more experienced instructors by serving as a backup instructor to the more experienced instructor.

Impact: Having the classroom has encouraged colleagues in chemistry and biology to adopt active learning pedagogies in their teaching:

"Other people have started teaching in the rooms and they also saw the efficacy of having students be able to interact with each other and be able to engage the students a little bit more actively in the classroom.... they have adopted the kind of learning environment that the classroom setup supports. So there's colleagues in chemistry and in biology who routinely request the SCALE-UP classrooms when we're not actually using them."

Institution $O$ is a doctoral-granting research university with approximately 15,000 undergraduates.

Initiation: The interviewee, a physics faculty member, was interested in SCALE-UP years before and had visited NCSU but did not believe it was possible to implement it at his university for unspecified reasons. Years later, his dean assigned the interviewee and another faculty member to investigate better teaching methods that could remedy high failure rates in an introductory course: "The dean had gotten a lot of complaints from [another department], 'cause they'd admitted [students] and they were absolutely perfect [for their major] on paper... and they weren't passing physics properly, or at an acceptable rate, so the dean charged me and a faculty member in math to research methods to approach this." 
Funding: After visiting another SCALE-UP site and receiving funds from the dean for their initial room, an old classroom was converted for a pilot of the innovation. This classroom received major renovation: removing previous features of the room. The pilot classroom featured large round tables and laptops with a capacity of 42 students. One of the challenges was that the first room was too small. The pilot had good initial results so the dean provided more funding to create more classrooms.

Characteristics of classroom: The interviewee recalled that the subsequent rooms received major renovation: "Three of [our SCALE-UP rooms] started classrooms with theater style seating-it was flat, but it was that; and the other three rooms were former labs; we just took everything out. In both cases, we took everything out and rebuilt." Although subsequent classrooms were also heavily renovated, these classrooms were slightly different from the pilot classroom. They changed the tables to D-shaped tables so students could see the board and interact with one another. They added projectors to the room as well. These rooms could accommodate 42 students.

Support for faculty: Some professional development has been offered. The university provided money to bring Beichner to run a workshop. Other support offer includes shadowing, weekly SCALE-UP meetings, and undergraduate learning assistants.

Impact: The math department started using more SCALE-UP style teaching. Numerous faculty members from other departments have seen the classroom and become interested in teaching in it. As the university is growing, the department is working on creating more SCALE-UP classrooms.

Although these three implementations occurred in different ways, they have similarities, some of which are shared by the other implementations. The following sections discuss common themes by answering the research questions.

\section{Research question \#1: how was the classroom space initiated?}

In order to have the SCALE-UP classroom space, adopters need to figure out logistics. At higher education institutions, this is often a collaborative decision because instructors typically share classrooms and do not have the power to renovate a classroom alone. This section delves into these aspects of SCALE-UP room implementation. In particular, we explore the important role of administrators in these implementations.

\section{Who was involved in the classroom space initiation?}

As mentioned previously, the development of SCALEUP classroom space often involves multiple people. The types of people involved in the implementations we studied are summarized in Table 1.
Table 1 Summary of types of people involved in SCALE-UP initiation

\begin{tabular}{llll}
\hline & $\begin{array}{l}\text { Initial source } \\
\text { of information } \\
(N=21)\end{array}$ & $\begin{array}{l}\text { Team creator } \\
\text { (out of 14 } \\
\text { institutions } \\
\text { with teams) }\end{array}$ & $\begin{array}{l}\text { Team composition } \\
\text { (out of 14 } \\
\text { institutions } \\
\text { with teams) }\end{array}$ \\
\hline Faculty & 11 & 4 & 14 \\
Administrator & 7 & 7 & 10 \\
$\quad$ University-level & 4 & 5 & 8 \\
$\quad \begin{array}{l}\text { Department chair } \\
\text { Faculty development }\end{array}$ & 3 & 2 & 2 \\
staff & 2 & 1 & 4 \\
$\begin{array}{l}\text { Non-instructional } \\
\text { staff }\end{array}$ & - & - & 3 \\
Unknown & 1 & 2 & - \\
\hline
\end{tabular}

The first step in implementing a SCALE-UP room is that an individual must learn about SCALE-UP and initiate discussions about the possibility of implementing it. The implementation process often began when an individual found out about SCALE-UP and began conversations that led to the adoption of SCALE-UP as shown in the institution $\mathrm{B}$ and $\mathrm{F}$ stories. Individuals reported learning about SCALE-UP through a variety of channels, such as conferences or site visits. These "initiating" individuals held a variety of roles in the institutions we studied:

- Regular faculty $(N=11)$

- University administrators $(N=4)$

- Department chairs $(N=3)$

- Faculty development staff $(N=2)$

- Unknown $(N=1)$

We note that the conversation starters are roughly evenly divided between regular faculty and individuals at higher levels in the institution (including department chairs, faculty development staff, and other administrators).

Although individuals started the conversations, a majority of implementations $(N=14)$ involved a team. Teams were created for a variety of reasons including generating interest from faculty and supporting staff who would undertake resolving logistical matters such as scheduling or equipment use. At institution $\mathrm{C}$, a university administrator created a team for pragmatic design reasons: "[The administrator] didn't want to just [create a room] based on what one person wanted; he wanted to make sure to include it in terms of all the disciplines and different ways people might want to use it." By including representatives from multiple disciplines, the room had greater potential to serve multiple purposes and ensure instructors' needs were met. Faculty also worked together to make sure that the curriculum was suitable for the classroom.

The nature of these teams varied considerably in their creation. Teams were assembled by faculty $(N=4)$, 
university administrators $(N=5)$, department chairs $(N=2)$, or faculty development staff $(N=1)$. For the other teams, it is unclear how they were created. The diversity of team creators in our sample suggests that "top-down" (administrator-driven) or "bottom-up" (faculty-driven) approaches can both lead to successful team creation.

The teams varied in composition (faculty, staff, administrators) and size. All 14 teams had some faculty participation. Teams also had participation from university administrators $(N=8)$, department chairs $(N=2)$, faculty development staff $(N=4)$, and non-instructional staff, such as a technology specialist $(N=3)$. Some teams were small and strictly faculty, while others were larger and included people in different roles. For example, as shown in two of our example cases, institution F's team was a pair of faculty while institution B involved a universitylevel administrator (the interviewee) and multiple faculty members (those who were serving on the committee to improve biology education).

Summary In our study, both faculty members and administrators initiated discussions about developing a SCALE-UP room. These individuals did not usually work alone to develop a room; implementations typically relied on teams. These teams were most commonly created by department heads or administrators and consisted of faculty, administrators, and staff. Having the team composed of both regular faculty and administrators is likely the most effective as both groups bring their own experiences, perspectives, and abilities to inform decisions related to the reform.

\section{Do initial teams have any subsequent impact on SCALE-UP spread?}

Although the primary purpose of the team is to create the initial room, the involvement of team members may not end once the room is created. Team members may work on creating additional rooms or encourage faculty who were not on the team to use the room or active learning techniques (i.e., spread the innovation beyond immediate team).

Other faculty members or departments that were not initially involved sometimes become interested in SCALEUP, helping the innovation diffuse or "spread" beyond the initial course or department and be used in other courses or departments. Of the five teams that mentioned spread, two faculty-created teams noted that SCALE-UP or active learning teaching techniques have been adopted by other instructors at their institution while three administratorcreated teams noted spread. The presence of an administrator on the team appears to impact whether or not SCALE-UP spreads throughout a department and/or to other departments.
These initial teams also can determine who controls the space and thus, who is allowed to teach in the room. When the university schedules the space, it can become easier for instructors from any discipline to use the space. Interviewee $\mathrm{R}$ explains

"[Our studio-style classrooms] are scheduled by our central classroom scheduling. Now the fact that the building is in a building that's called [biology] building, means that, means that I guess we have a little nod to priority... But other people had access to teach in it."

Other times, the department that starts the innovation has first-priority access to the space. Interviewee E-1 noted that multiple classrooms were created in his department's building and indicated that the rooms were primarily for their department's courses. Because they decided to teach all the sections of one large introductory course in the studio-style, instructors were assigned to these rooms. Subsequently, another course within their department was converted to teaching in the studio-style. This suggests that university-controlled space may be better suited for spreading SCALE-UP around the institution, while department-controlled space may be better suited for spread within the department.

Summary Having an administrator on teams can help encourage spread of SCALE-UP. University-level administrators can help spread through converting courses to use SCALE-UP or creating university-controlled spaces and allowing others outside of the department to use it.

\section{How was the room financed?}

Although the costs can vary considerably, funding is almost always needed to create a SCALE-UP room. A lack of funding for redesigning a room is a challenge (Foote et al. 2014), but as our interviewees indicate, this is a challenge that can be overcome.

Table 2 displays the different funding sources for the initial room. Most interviewees reported that funding came from the institution $(N=14)$. Within institutions, though, funding sources varied considerably with approval provided by department chairs, deans (e.g., dean of academic affairs, dean of the college), the provost, the institution's president, and facilities management. Typically $(N=17)$, this funding was used to convert existing classroom space into a SCALE-UP room and included minor renovations as well as purchasing furniture, technology, and white boards. In some cases $(N=4)$, funding for the initial SCALE-UP room occurred as part of a new building or scheduled renovation rather than a separate initiative focused only on implementing SCALE-UP.

The means of gaining approval for institutional funds varied considerably and include 
Table 2 Funding sources for the initial room

\begin{tabular}{lll}
\hline Funding source & $\begin{array}{l}\text { Count } \\
(N=21)\end{array}$ & Example source \\
\hline $\begin{array}{l}\text { Institutional (department } \\
\text { and university) }\end{array}$ & 14 & Provost \\
External/government funding & 4 & Education improvement grant \\
Unknown & 3 & - \\
\hline
\end{tabular}

- Direct contact with a university-level administration $(N=7)$. Some interviewees simply had a conversation with a university-level administrator and asked that an already scheduled renovation include a studio-style classroom. One interviewee gave a presentation to the provost that featured data they had collected on learning gains from an active learning pilot classroom and were granted funds for a more suitable SCALEUP classroom. A different interviewee sent out a general invitation on an institutional email list, inviting interested parties to her classroom to observe the active learning techniques she was using in a traditional classroom. An administrator attended one of her classes and became interested supporting these efforts.

- Contact with the department chair $(N=3)$. Department chairs sometimes helped instructors in their department obtain funds from institutionallevel administration. Details were not provided.

- Using connections on a previously existing team to obtain funding $(N=4)$. Interviewees were a part of a team tasked with improving undergraduate education. They sometimes recommended SCALE-UP to achieve these goals.

As a repeating pattern, we find that there is not one way and many possible avenues can lead to success.

Although institutional funding was the most common source of funding, it was not the only source. Another funding source was external/government funding $(N=4)$. At one institution, the faculty had received an external grant prior to considering SCALE-UP and was able to use that money to redesign the classroom. Another institution partnered with the SCALE-UP developer to write a grant proposal for external funding. Similar to university funding, these funds were used to renovate existing instructional space into a SCALE-UP classroom.

In institutions where subsequent rooms were developed, funding sources were similar to the first room. In one case, an institution received financial support for subsequent SCALE-UP rooms from alumni.

Summary Our interviewees primarily funded their SCALE-UP room from the institution, drawing from different offices. There is no "right" person or office to ask for funds nor is there a "right" approach for asking; internal funding sources varied considerably from implementation to implementation. While simply asking for funding worked for some of these interviewees, others demonstrated the benefits of active learning use to argue that a more suitable classroom would be an asset for their teaching. Others were working in a team to improve undergraduate education and used the opportunity to propose SCALE-UP. If a renovation project is already scheduled with allocated funds, implementers may just need to request a SCALE-UP style renovation. We note that finding funding was not always easy for our interviewees. Identifying a receptive audience and presenting SCALE-UP as a solution to an administrator concern (e.g., high DFW rates) can help.

\section{Research question \#2: what are the characteristics of the classroom space?}

When planning to develop a SCALE-UP room, it is necessary to carefully think about the characteristics of the room. This section examines the room characteristics identified by our interviewees and compares these to the room characteristics suggested by Beichner.

Initial SCALE-UP classrooms typically involved renovating existing space $(N=17)$. Classroom renovations varied in scope from adding a few pieces of equipment and furnishings to significant construction, depending on what was already available. This suggests that a classroom may only require minor modifications to be used as a SCALEUP classroom if the classroom already has some of the suggested features.

\section{How did the implemented classroom characteristics compare to the recommended classroom characteristics? Which classroom features are helpful? Unhelpful? Non- essential?}

Implementers need to make decisions about which room features to include in a SCALE-UP room based on available resources and constraints (e.g., funding, typical class sizes). We were interested in which features were included in each of these successful implementations and how important they were to the interviewees.

Although some features are explicitly absent, some features may be present but just not mentioned by the interviewee. We did not explicitly ask the interviewees about the presence of each feature, but general questions regarding what was in their SCALE-UP rooms and what they found helpful and unhelpful. As is the case throughout this paper, it is important to keep in mind that these were open-ended interviews. Interviewees may have commented on more features if we had asked them directly.

Although not a room characteristic, three interviewees explicitly stated that having a dedicated classroom in general was helpful. For example, the interviewee from 
institution J explained: "it's the pedagogy that is facilitated greatly by the classrooms." The interviewee from institution $\mathrm{R}$ elaborated on this point: "That the space itself, and maybe I had not appreciated how much of our behavior is driven by the physical environment in which we are. And so the room itself can be a partner or a barrier in whatever it is that you want to do, and for active learning it's an enormously powerful partner." Some implicit evidence suggests that the dedicated room is helpful; one or more additional classrooms were created at 16 of the institutions, and 2 institutions indicate that they would like to have additional classrooms.

As for the details of the room, Table 3 shows the frequency of room characteristics reported by the interviewees. The categories are the recommended features as noted by Beichner on the SCALE-UP website. We included a broad "technology" category to encompass features such as computers, projection screens, and other items that are colloquially referred to as technology, because some interviewees were not specific. We note whether the specific characteristic was explicitly mentioned and also indicate how frequently the mentioned features were noted as being helpful, unhelpful, or nonessential (an item that did not hinder teaching but could be removed without affecting the use of the pedagogy).

Few features are explicitly absent. Some of these features were likely present even if they were not mentioned. For example, poor acoustics are usually noticeable because they make communication difficult, but good acoustics may go unnoticed and unmentioned by the interviewee.

Sometimes, implementers need to make deviations from the recommended features based on various factors including budget, classroom needs, and room geometry. The interviewee from institution $J$ stated that one department deliberately chose a different table design for a combination of the aforementioned reasons:
"There's a single screen and they set that up for a particular approach [for that department]. It's a small room and they wanted everybody focused on the same image at the same time, but they also wanted to do team-based inquiry guided learning, so they can do that at those [crescent-shaped tables], and it's not very cash heavy at all, it didn't cost much money. They decided there was this particular need served better by these tables and a front to the room."

This department demonstrates that one may be able to find a way to balance the needs of instructors with different instructional styles.

The frequency of features mentioned by interviewees is similar to previous survey data (Foote et al. 2014). The following subsections delve into the details of why interviewees perceive features as helpful or not.

Features that support collaboration are perceived as helpful Tables to promote group interactions and white boards are among the most frequently mentioned features. While many users follow the suggested large class model and use large round tables, other users choose different shapes including D-shaped tables, hexagonal tables, and cross-shaped tables.

In addition to being the most frequently named features, tables and white boards were also most frequently named as helpful. Interviewees named tables for students $(N=7)$ and whiteboards $(N=5)$ as a helpful room feature, because they help students to interact with one another. Although they are separate features, tables and white boards work in conjunction to support peer collaboration as the interviewee from institution $\mathrm{T}$ noted: "What people really say they love are the whiteboards and the round tables, students working in teams."

One specific benefit of the collaborative workspace is that the students can see that they are not the ones

Table 3 Current room characteristics mentioned in interviews $(N=21)$

\begin{tabular}{|c|c|c|c|c|c|}
\hline Feature & Explicitly present & Explicitly absent & Helpful & Unhelpful & Non-essential \\
\hline Tables to promote group interactions & 21 & - & 6 & - & - \\
\hline Technology $^{a}$ & 21 & - & 3 & 2 & 2 \\
\hline Video screens & 12 & - & - & - & - \\
\hline Computers for student use & 10 & - & - & - & - \\
\hline Instructor station for use & 7 & - & - & - & - \\
\hline Student white boards & 17 & - & 5 & - & - \\
\hline Rolling, armless, un-upholstered chairs & 1 & - & - & - & - \\
\hline Large enough room to avoid crowding, as close to square as possible & - & 3 & - & 3 & - \\
\hline $\begin{array}{l}\text { Adequate space between tables to facilitate instructor roaming } \\
\text { (absolute minimum table spacing of } 5^{\prime} \text { edge to edge) }\end{array}$ & - & - & - & - & - \\
\hline Good acoustics (carpeting, ceiling tile, quiet HVAC) & - & - & - & - & - \\
\hline
\end{tabular}

We noted both the general use of technology as well as specific types of technology. Because implementers sometimes use multiple types of technology (e.g., video screens and computers for student use), the general technology category and the sum of the specific technology categories are not equal 
challenged by the material, as the interviewee from institution R explained

"That table creates a little microcosm, a supportive microcosm that helps you be part of a-you're not alone, you're not suffering alone, you're not struggling alone; you're realizing that it's a hard thing that everybody in the team is having trouble with that idea, or you know, 'I'm just as smart as everybody else' and I think there's real power in that from the student perspective."

As this interviewee suggests, the interactions can bolster student confidence and efficacy.

The table setup also benefits student-instructor interaction. Interviewee E-1 explained why tables are helpful

"[One important feature to have is] student tables that foster peer instruction and group work and instructor access. From the instructor standpoint, when I taught SCALE-UP without the tables, it was really, really hard because I couldn't get easily to the students. It was like a gymnastic act to get into the middle of a long row to talk to a particular student or student team."

Flexible classrooms are perceived as helpful Some interviewees $(N=4)$ felt that having a flexible classroom, one in which they can rearrange all furnishings and equipment, was helpful. The interviewee from institution G liked being able to experiment with the room arrangement and recommended the following:

"If you want faculty to innovate with set-ups in a classroom, it's got to be lightweight, something where the students themselves or the faculty can rearrange them in a couple minutes 'cause otherwise you're kind of stuck there unless you hire a crew to come in and move the tables around for you."

Beyond personal experimentation with the classroom configuration, it may be beneficial to have particular features that can be rearranged for students. The interviewee from institution $\mathrm{N}$ noted they designed the room to have movable smart boards: "The Smart Boards were also on movable stands, rather than attached to the walls, so they could be moved to whatever positions were suitable for the groups, while still making sure that everybody could see them."

Technology's usefulness is complicated While all interviewees noted some kind of technology was present in the rooms, it was often unclear as to whether it was helpful, non-essential, or unhelpful as either a general category and with specific types of technology (e.g., computer-based activities). Various pieces of technology were noted as helpful by three interviewees, for reasons ranging from generating faculty interest in the room and overcoming a room shape challenge to communicate with students to making some student activities easier. Some interviewees $(N=3)$ noted that they wish they had better technology in the classroom, with two who were unspecific and one who thought a remote control system to access the instructor computer would help overcome a difficult room geometry. It is interesting to note that similar to the interviewee who had communications troubles, this interviewee's use for technology was not to enhance student learning but to overcome room constraints.

However, technology is not always considered necessary in SCALE-UP classrooms. Two interviewees noted that technology was not helpful, with one due to time constraints, and two noted it was non-essential, believing that instructors can use active learning without computers.

While our results do not contradict prior research and resemble some of the challenges present in K-12 and higher education, they do suggest technology use for this style of teaching may be more related to instructor concerns or classroom layout issues rather than more directly to student engagement or learning. Technology may be more useful for student learning with better professional development.

Awkward room geometry and too small classroom size is perceived as unhelpful Few of the interviewees mentioned anything about the room size and shape. Those who did, however, noted that the room geometry was an issue $(N=3)$. Some of the rooms have layouts where students have difficulties accessing the instructor or seeing presentations, such as the L-shaped room at institution $\mathrm{B}$ or the long rectangular room from institution D-2. Some rooms are not large enough to accommodate as many students as the instructor would like. Although this may be an obvious issue to some, this is an issue where prospective implementers should be conscientious and perhaps advocate for a more suitable space.

Summary Having dedicated classroom space for SCALE-UP is important to encourage active learning. Although the recommended characteristics help facilitate studio-style teaching, successful SCALE-UP implementation may not need all the recommended characteristics. Deviations to the suggested model can work well as long as they are thoughtfully adapted to consider the purpose of the characteristics and the needs of the implementer. 
While some deviations from the suggested room design can work, maintaining the intent of the recommended features is important. Interviewees specifically noted that features that allow for student collaboration (e.g., tables and white boards) are beneficial for both student-faculty and student-student interactions. The tables and whiteboards facilitate these interactions.

Instructors saw some value in having flexible classrooms, ones that can easily be rearranged. The flexibility appears to be for specific purpose, such as personal interest in experimenting with classroom configuration or overcoming a room shape. The authors of this paper acknowledge that these specific reasons are valuable to these users and that some features, such as chairs, benefit from mobility. However, we also note that too much flexibility means that the classroom can revert back to its original, pre-SCALE-UP state. Adopters should consider the purpose of having a flexible classroom and how flexible the classroom should be.

Technology was met with mixed results for SCALEUP implementation. Our interviews identified that technology, in general, can help overcome difficulties in the room, but it does not seem to be the most critical aspect of a SCALE-UP room. For example, if the room has a poor layout, technology may be almost imperative to facilitate interaction. However, in many cases, it appears possible to develop a successful room with minimal technology.

Classroom size and geometry can be a hindrance if the room is too small or makes accessing students difficult. Because most SCALE-UP implementations happen in renovated classrooms, users may not have control over the geometry or size. When possible, as noted by Beichner, the room should be as close to square-shaped as possible so that the instructor and other staff can access all students easily.

\section{Were additional classrooms built? If so, did subsequent classroom differ from the initial model?}

Sites that begin with one SCALE-UP classroom often build additional classrooms so more instructors can teach using active learning techniques. We were interested in whether secondary adopters made any modifications to subsequent classrooms (e.g., choosing a different layout or different furnishings) and if so, why.

The majority of sites $(N=16)$ built additional rooms. They generally did not make major changes to their initial room design, suggesting that the design of the initial rooms were considered to be sufficient. When differences in subsequent rooms occurred, they often arose because of local logistics of new rooms to be renovated, such as size or shape rather than because features of previous rooms were deemed inadequate.
One implementer did intentionally change the initial room design in subsequent classrooms. The interviewee from institution Q did not have an ideal initial classroom due to institutional constraints. Students sat at long lab benches around the room. Upon institution Q's administration obtaining money for SCALE-UP rooms, they were able to renovate classrooms. The interviewee, comparing the new space to the previous room, remarked

"It was night and day. The old one, some of the students were facing in the wrong direction. They really couldn't get together as groups and we didn't have much in the way of technology in the room. The new ones are really nice."

The newer classrooms had major improvements that made the classroom look like a typical SCALE-UP room. Subsequent classrooms contained tables for students to easily work in groups and technology (computers, lab equipment) that allowed for the student groups to work concurrently, without waiting for another group to complete their work. Institution Q's changes to the classroom speak to the importance of having furniture that allows for group work and how technology can be used effectively.

Summary Subsequent rooms are typically similar to initial rooms. This suggests that institutions are happy with their initial room designs and perhaps can be attributed to careful planning and use of resources such as those by Beichner on the SCALE-UP website, which all interviewees had access to, or through interacting with a SCALE-UP user. Knowledge is not enough, however, if the implementers cannot obtain key pieces such as suitable furniture.

\section{Research question \#3: what training or support was offered to instructors who teach in the redesigned classroom space?}

Professional development has been emphasized in other work in order to ease the challenges instructors face in teaching in an unfamiliar style (Cummings et al. 1999; Rogers et al. 2015). As SCALE-UP is a departure from traditional teaching, instructors may be unsure how to change their practice and feel disoriented in the classroom. We were interested in the ways that instructors at these successful implementations learn how teach effectively in the room and what kinds of support (e.g., teaching assistants) are available and helpful. In this section, we examined the kinds of professional development and support that are offered to the instructors who use these rooms as well as why implementers offer training. 


\section{What kinds of support or training are provided?}

Fourteen implementations mentioned offering training for users of the SCALE-UP room. The interviewee from institution $\mathrm{O}$ pointed out that active learning techniques may not have been experienced by instructors in any context: "you have to learn a different set of teaching skills [to teach using SCALE-UP] than probably you were exposed to as a student." The interviewee from institution $\mathrm{R}$ observed that lack of training prevented SCALE-UP use at a different institution: "I was at one place where the room was not used most of the time. They had invested a whole bunch of money, but the faculty weren't trained to use it yet. That to me just seems really not a good idea." Similarly, the interviewee from institution P preemptively created a professional learning community to support faculty teaching.

Training can help screen potential users of the room. The faculty member from institution $\mathrm{T}$ observed the need for instructor training for this reason: "We wanted to know why they needed that space. It's a huge capital investment so we wanted to know that whoever was teaching in there was converting their courses appropriately." Institution $\mathrm{T}$ requires that instructors apply to use the room and are trained.

The types of professional development offered at the 14 institutions that discussed professional development in the interviews include the following:

- Formal training programs $(N=6)$

- Instructor shadowing $(N=5)$ and

- Informal training programs (often organized by the implementer) $(N=3)$

At most institutions, training is optional $(N=11)$, while for others training is required in order to use the room $(N=3)$.

Formal training consisted of structured activities, such as the professional learning community at institution $\mathrm{P}$ or workshops. The length of formal training in our case studies varied from a 1-day session to multiple sessions over an academic semester. For example, institution $U$ offers a weeklong training prior to the beginning of the academic year. The interviewee from institution $U$ described

"I would actually sit [the faculty] through my own [weekly studio course]. Teaching them what the class should look like, I kind of modeled the best practices and taking them through that. They actually would spend time working in groups completing these new labs, learning how to use the software, learning how to use the sensors, going through all of that process. I would have them write reflections at the end of the day, I would have them work together in groups, and all, any of the techniques I was using, I wrapped that into the course to help them teach them about the new technologies available in the room, the new lab equipment, what this should look like."

Shadowing, a specific type of informal training, entails observing a current instructor and occasionally, assisting with classroom activities once the novice instructor feels more comfortable. An example of shadowing is what institution $\mathrm{H}$ does

"The best plan is that they come into my class and they spend the semester with me and see how it goes. I would hand off my stuff to them, and they would do it. So that's kind of the training program, if you will, it's a loose program. So there's no rigorous training, there's no boot camp to go through. We don't... leave someone to sink or swim; that would be bad."

Informal training can include unstructured faculty mentoring. For example, an experienced instructor might guide a novice instructor. Instructors may chat about teaching in the SCALE-UP room and offer advice. These conversations may lead to an informal learning community for instructor, where instructors troubleshoot and problem solve. This was the case with interviewee D-1's efforts to offer support for instructors. Faculty started by sharing course material, but then they became part of a "collaborative of people sharing new ways that they've tried to get across a concept or new ways of approaching a laboratory or how to integrate the laboratory with the concepts so they share all kinds of materials."

These three types of professional development suggest that there are multiple ways that instructors can become familiar with SCALE-UP. Although they may take different formats, the information may not be radically different. For example, the shadowing at institution $\mathrm{H}$ and the formal training at institution $U$ both expose novice users to what the classroom and teaching in the classroom look like.

Although the implementers who offered professional development focused on completely inexperienced SCALEUP instructors, continued professional development may also help. The interviewee from institution $U$ noted that some instructors enroll in training more than once

Some people might have even gone through the experience twice because "Oh, I'm not teaching it in the fall but who knows, I might be doing it in the spring," and so they would ahead and go through the workshop. And then they would go through the workshop again, [with the mindset of] "Okay, I've got a feel now but let's dig a little bit deeper." 
Simply revisiting the material may be enough for faculty to gain more out of the material.

Professional development of undergraduate and graduate teaching assistants Because SCALE-UP entails a high-level student-instructor interaction, we were interested in what types of additional teaching staff is available to help with numerous groups and how this teaching staff is prepared to teach in the classroom. As our interviewees have indicated, training is necessary for instructors teaching in these classrooms. Is it also necessary for teaching assistants?

Approximately half of these institutions use undergraduate or graduate teaching assistants to support instruction in the SCALE-UP rooms $(N=10)$. All of the undergraduate teaching assistants $(N=5)$ are called learning assistants, and the majority $(N=4$, with 1 unclear) adopted the University of Colorado's Learning Assistant model, which includes a pedagogy course for their training.

Extra teaching staff helps ensure more students receive the help they need, as described by the interviewee from institution $\mathrm{C}$

"One of the things we did when we did the large classrooms was we also included learning assistants, undergraduates, to help out with the group work and just be a bigger presence in the classroom to move around and handle those large numbers of students, help assist the faculty member with answering questions and things like that."

The learning assistants, who often have previously taken the course in which they work, serve a unique role in the classroom. They are able to act as role models for the students currently enrolled in the course and help them adjust to SCALE-UP, as the interviewee from institution $\mathrm{R}$ observed

"I think that having the reality of somebody who's been through this class before and has learned to, has figured out how to learn well in that modality and has gone through the frustration, 'cause students are very frustrated that they aren't just lectured to and entertained; we found that early on to be very helpful in helping students come to grips with having to do something in class rather than just sit there."

Although learning assistants are enrolled in a pedagogy course, they may receive additional training to support classroom activities. According to interviewee E-2, the institution has begun to create increasingly structured training materials to encourage faculty instructors and undergraduate assistants to use inquiry-based methods
"We developed guiding questions that we would prepare our people with, both our faculty and our undergraduates, so that when students got stuck, rather than drifting toward just telling them what to do, they had more and more tools for helping the students push into a discovery of their own."

Although relatively rare $(N=2)$ in the cases examined in this study, training may be important to train graduate teaching assistants as well. The interviewee from institution $Q$ explained why the institution felt teaching assistants needed additional training

"It took us a while to realize that the graduate students needed training. We talked to them. We had some really two brief orientation sessions at the beginning of the year. But I want to say that we frankly were a little bit remiss, I guess, in not giving them more introduction into what it was we were trying to do."

At institution $\mathrm{T}$, graduate students meet with the faculty instructors. She notes that these meetings depend on the faculty; some faculty may not provide any training for their graduate teaching assistants.

Summary Our interviewees found that professional development was necessary for faculty teaching in these rooms. Training can help instructors who are unfamiliar with SCALE-UP learn to teach in the room effectively and feel more confident in their ability to do so. Our interviewees demonstrate that professional development does not have to take one form, but there are common threads of showing novice SCALE-UP instructors how to teach in the classroom.

Like faculty, undergraduate and graduate student teaching assistants also benefit from professional development. If a department or institution adopts a learning assistant program, some of the training in active learning techniques may already be provided. Developing guides with examples of what questions to ask students may also be useful. In the case of institution Q, providing information on SCALE-UP through a short orientation is a small but perhaps important step.

\section{Did implementers need to modify subsequent support and training from their initial implementation at the institution?} Similar to why we were interested in whether modifications were needed for subsequent rooms, we were interested in whether implementers changed the professional development that they offered. Changes can provide insight to any challenges that the implementers found with their initial training offering or give clues as to what information and training should be included. 
Of the 14 implementations providing professional development, only seven did from the beginning. The other seven added professional development, with two interviewees noted that this was done based on a recognized need. For example, one interviewee began weekly meetings when he realized other instructors were not using the room effectively. Another interviewee discussed adding training, because the instructors who would be using the room requested training. The motivations for adding training are unclear for the other five implementers, but some of these implementers were initially the only person teaching in the classroom. Perhaps they realized how daunting teaching in such a room could be and sought to lower the learning curve for subsequent users.

\section{Research question \#4: what indirect effects did the new classroom space have at the institution?}

SCALE-UP focuses on activities and teaching within courses. In our interviews, we noted additional indirect benefits to institutions that developed a SCALE-UP room. Frequent themes included institutional pride (the institutions use the classroom as a positive symbol to show guests) and expanded active learning techniques beyond courses taught in the SCALE-UP room.

\section{Institutions use the room to promote their image}

Four institutions report that the SCALE-UP room is a source of institutional pride. Administration likes to show off the room to prospective students and other guests, for example, on a campus tour to prospective students or alumni.

The room can also ignite interest for alumni to donate. One institution was able to attract alumni support to fund further SCALE-UP construction. Interviewee E-2 described how this happened

"While classes were in session, we'd invite [alumni or esteemed visitors] into our classes, but if classes weren't in session, we would hold a class for other people so they could see what we were doing. It resulted in additional support coming from the alumni base. Partially the idea was [to engage] the donors who aren't really interested in building a new building, and donors that aren't really interested in a statue or whatever. Some of those donors will be really interested in supporting a learning space, especially if they see the way that it works. That was another thing that was a conscious effort on our part to attract more money, more people, more converts to the movement, as it were."

\section{Building and using the room encouraged active learning techniques more broadly}

Eleven interviewees observed an increased interest in reformed teaching from other faculty or themselves, including an increase in teaching workshop attendance. Some of this may be creating an awareness of active learning techniques by offering professional development. The interviewee from institution $\mathrm{L}$ noticed that knowledge about science teaching varies from instructor to instructor: "I did a couple sessions myself on how do you teach active learning, how do you teach active, some of those people were already doing that, some people had some things to learn." While the provided professional development is primarily to help instructors learn how to use the room, there is greater benefit of faculty broadening their teaching repertoire.

This increased interest can change their instructional practices in classes that are not taught in the SCALE-UP classroom. Teaching in the SCALE-UP room is not always possible because of space (e.g., laboratory safety restrictions) and scheduling restrictions. Three interviewees said they started teaching their traditional courses differently, and three interview participants said they have more of a personal interest in generally using active learning techniques. The interviewee from institution $\mathrm{F}$ described the impact of teaching in the room on her teaching practice beyond teaching in the special rooms

"I would say that like say, for example, in my upper division classes, I use a lot of the same kinds of techniques. I very rarely talk for very long, you know, so I really try as much as I can to make the students active in class in a variety of different ways... I taught a lecture-based physical science course for nonmajors... using all the same methods and techniques in that class as well. For me personally, it doesn't make any sense to me to just try to talk to people and think that they're going to get it, you know?"

This suggests that teaching in the room can be transformative for the instructor.

Summary The SCALE-UP room can be leveraged to engage multiple populations and support institutional concerns outside of teaching. These include recruiting students and seeking funding from alumni. A SCALEUP room also has additional benefits for teaching practice. Our findings suggest that the classroom can support the spread of active learning teaching techniques to other faculty and other courses taught in more traditional rooms. The presence of the classroom can aid the development of an institutional culture that is invested in teaching reforms.

\section{Discussion}

Our ultimate goal was to study successful implementations in order to offer guidance to those seeking to implement a 
SCALE-UP-like reform at their own institution. Although each of the 21 SCALE-UP implementations we studied had unique initiation and implementation stories, we saw patterns that provide useful information for either future implementations or those wanting to improve current implementations. These data contribute to the current body of research providing insight on why and how secondary implementers modify the SCALE-UP innovation, what support can help instructors effectively use the room, and what additional impacts these classrooms can have on institutions and instructional practice. Below, we highlight and discuss recommendations that came from our analysis of these cases. While in many ways these recommendations may appear obvious, we are aware of many reform efforts that do not follow them.

\section{Recommendation 1: initiate the reform as a team}

As described above, all of the successful implementations we studied were the result of working with others. Many of these included a diverse group of individuals. This finding is in alignment with the finding that successful implementation should take place in a supportive environment (Klein and Sorra 1996; Zhu and Engels 2013) and that collaboration tends to be more successful than individuals attempting to implement an innovation (Zhu and Engels 2013).

A team approach (in contrast to the individual superhero model which we anecdotally find common in reform efforts) appears to have numerous benefits. Namely, we identified three primary benefits

1. Garnering interest across the department and university for building, supporting, and using a SCALE-UP room. Team members may have strong relationships with key administrators or access to resources. Interviewee E-1's initial classroom was funded because of help from his department chair asking the provost: "Our department chair was good at negotiating, you know, 'you give me this I'll give you that' kind of thing."

2. Creating a room that is serviceable for multiple users. Our interviewee from institution $C$ pointed out that including perspectives from different disciplines can help create a room that suits multiple needs. Other users, regardless of discipline, may have preferences as well. This may help encourage more users for the room.

3. Receiving input from support staff to ensure smooth operations. Besides faculty, there are others involved with the day-to-day operations of a course. SCALEUP usage often means staff may have to change their current systems. The interviewee from institution D identified seeking the technical staff's involvement, because they would have to "...do the nuts and bolts of putting these laboratories together."
Recommendation 2: include an administrator (departmental or institutional) on the team. Involvement of an administrator from the beginning can increase the likelihood that the implementation spreads to include more departmental courses and/or spreads to include more departments

Wejnert (2002) identified that the inability to modify organizational structures is a constraint to educational innovations. Our work may have found a way to mitigate this constraint. While administrators cannot completely overhaul the structure, they are positions to make changes as we saw in our data. Having an administrator on the team has clear benefits as administrators have the most control over university structures such as funding, scheduling, and professional development support. As we noted, most rooms in this study were built using internal funds that were provided by the administration. In short, getting administrative buy-in is important and getting buy-in is easier if administrations are part of the reform initiation team. By including an administrator from the beginning, the administrator likely will have better understanding of the innovation and its potential to improve student learning. At institution $\mathrm{O}$, the dean asked our interviewee to seek out a solution for high failure rates in an introductory class. The dean was able and willing to invest more money into creating more classrooms after the initial classroom demonstrated promising results. The lack of buy-in from an administrator can also be issue for even simple changes, as interviewee from institution G saw: "I mean literally for, like, from 2002 until around 2000, let's say, 2008, I kept saying let's move them around and the chair just didn't do it."

In addition to increasing access to resources, administrators can help to spread the innovation through and across departments. For example, they can facilitate the collection of feedback to ensure rooms are built suitably for multiple disciplines as described above. Administrators can also facilitate spread by assigning others to the space or deciding to convert multiple traditional classrooms into university-controlled spaces available to faculty in other departments. Having multiple classrooms and multiple instructors using the classrooms may also help sustain innovation use. Multiple classrooms mean more instructors can access the innovation, and multiple instructors using the innovation means that the continued use does not rely on one individual.

\section{Recommendation 3: persist in your search for funding to build a room and think creatively}

Potential SCALE-UP adopters are often concerned about how to pay for a room. The perceived belief that funding is impossible leads efforts to cease. While we agree that funding is necessary and sometimes difficult to obtain, 
the stories of the implementers in this study demonstrate that it is not impossible and that it can be obtained through creativity and perseverance.

We note that there was no clear pattern of how funding was obtained, rather implementers found a variety of solutions. The funding sources ranged from alumni funds to grants to different institutional units, and the ways the sources were approached ranged from simple conversations to presentation to receiving help from one's department chair. This finding is reminiscent of Henderson and Dancy's (2011) finding that secondary implementers may need to make adjustments to educational innovations for their institution's characteristics. Those interested in obtaining a room should consider their institution and adjust accordingly when crafting their requests for funding. Knowing whom and how to ask is dependent upon the local situation.

\section{Recommendation 4: be creative and resourceful in looking for classroom space}

SCALE-UP rooms can be created from many different types of classroom space. Our interviewees' initial classrooms had many different formats, ranging from space in a new building to rearranging a pre-existing classroom and adding a few key pieces. This suggests that there is not one "right" type of space and that implementers should not feel that creating a SCALE-UP room involves heavy construction. The literature broadly finds that innovations are customized to local conditions (Henderson and Dancy 2011); the choice in classroom space is a reflection of local conditions. If there are opportunities to choose the space, issues such as whether students can see the instructor should be considered.

It is important to stay up-to-date with the institution's plans. Perhaps construction projects for new or renovated space can accommodate a SCALE-UP room. Otherwise, be aware of the possibilities of currently existing space. There may be classrooms available that require few modifications to work for a SCALE-UP room.

Recommendation 5: when designing a room, give priority consideration to features that facilitate collaboration and enable flexibility

Implementers, faced with constraints and their own unique outlook, may wonder how essential it is to follow all suggested features. No two implementations among our successful sites were identical, with the implication being that some modification is fine. However, two features rose to the top of those mentioned by implementers as being most helpful: those that facilitate collaboration and those that enable flexibility.

Despite differences in the details, all of the SCALE-UP rooms were designed to facilitate peer-peer and peer- instructor interaction and many mentioned this explicitly as a helpful feature. Studio-style reforms were created to foster collaboration (Beichner 2014), so it was not surprising that special tables and whiteboards were seen as helpful. However, we have seen attempts (with poor results) to implement SCALE-UP philosophy without these structures in place (i.e., trying to make it work in a traditional lecture hall with the chairs bolted down). Our interviewees highlight that collaborative classroom features are a priority for success. As described by the interviewee from institution $\mathrm{R}$ in the "How did the implemented classroom characteristics compare to the recommended classroom characteristics? Which classroom features are helpful? Unhelpful? Non-essential?" section, the collaborative features are not just about ensuring students understand the concepts but also helping students recognize they are not the only ones who do not understand the material.

Along these same lines, having flexible arrangements in the room was reported helpful. Every instructor has their own unique ways of teaching and having an adaptable classroom space encourages a wider range of individuals to use the space. It also helps them maximize the impact of their unique teaching style.

Finally, we note the mixed response to the helpfulness of technology. While most interviewees did not go into detail about specifics, technology was not named as a must-have for the classroom activities. The literature provides some possibilities as to why technology is not critical, ranging from instructors not using technology well or not modifying their teaching to incorporate it (Cuban 2001; Lasry et al. 2014) to unreliable technology (Cuban 2001; Frank et al. 2004). Some of the helpful aspects of technology were circumstantial, e.g., to help mitigate less ideal classroom environment such as room shape. One interviewee indicated it was helpful for getting faculty interested in teaching in the classroom but non-essential for classroom activities. This indicates that technology can be helpful, but that if space and/or finances are an issue, it is likely that SCALE-UP can be implemented successfully without it. Technology is just a tool after all, and in and of itself does not dictate the benefit of its use.

\section{Recommendation 6: incorporate professional development into any implementation of SCALE-UP}

The literature demonstrates a clear need for professional development when adopting innovations (Cummings et al. 1999; Chasteen et al. 2011; Florman 2014; Rogers et al. 2015). Our interviewees supported the need for professional development as evidenced by both the statements they made directly claiming professional development was important as well as the fact that half 
of the sites started without it but then added it as they recognized its importance.

Even for experienced and highly competent instructors, teaching in a SCALE-UP type classroom is a novel experience that requires new skills and support. Expecting instructors to enter a new classroom without any support learning to teach in the new environment is less likely to lead to a successful outcome. It can be particularly problematic if an instructor has a bad experience in the reform environment and then turns away from this type of teaching and/or makes negative comments about the experience to other colleagues. Instructors are more likely to have positive experiences, to keep teaching in this style, and to help spread the reform when they receive professional development.

Recommendation 7: make the SCALE-UP classroom visible to improve teaching across the university and to increase sustainability of the room

As mentioned above, our analysis indicates that a highly visible room advertises active learning techniques and increases instructor interest in active learning techniques. This leads some instructors to use reformed pedagogies in non-SCALE-UP rooms. Thus, the benefits of SCALE-UP extend beyond the immediate active learning classroom. Even if it does not specifically lead to increased SCALE-UP usage, it can lead to improved teaching in other classes.

An additional benefit of a visible classroom is that it looks impressive. We found that several institutions use rooms to attract and impress prospective students and alumni, for example, as part of the campus tour. This likely benefits the sustainability of SCALE-UP on the campus, as it becomes a part of the institution's identity. Interestingly, the room for one of our abandoner case was in a building that was not typically used by the implementer's department. Encouraging administration to show off the classroom to gain support for the room and SCALE-UP, implementers can suggest that the room is a featured destination for guests on tours or for meetings to be held in the room.

\section{Conclusions}

Despite our efforts, we found only one definite abandoner when there are 259 known SCALE-UP secondary implementers from the past 20 years. In contrast, approximately one third of all faculty who try a researchbased instructional strategy will eventually abandon it (Henderson et al. 2012). Why does SCALE-UP achieve a higher rate of sustainability? While we cannot definitely answer this question, we can offer educated hypotheses and suggest future research.

Before embarking on this study, we knew SCALE-UP has positive results (i.e., documented learning gains, retention rates) and that faculty typically enjoy teaching in this environment, but is that enough to create sustainable change? While this is true, it is also true of other reforms that are more frequently abandoned. So we believe this is a necessary but not sufficient for high sustainability.

We hypothesize that radical, structural changes associated with SCALE-UP increase sustainability. Specifically, the team effort needed to implement the structural changes required to redesign a classroom space. As presented and discussed above, fully implementing a SCALE-UP reform typically involves a team effort, often with administrators on board. By the time SCALE-UP is implemented, there usually have been many conversations among many individuals with different perspectives, motivations, and interests. We believe these discussions (and likely debates, compromises, etc.), which may seem difficult at the time, eventually pay off with more buy-in across parties in the long run. This investment across different levels of an institution likely protects the reform even if the situation changes.

We also hypothesize that SCALE-UP is protected against abandonment because once an investment is made, it would require significant effort to undue the reform. Just time and money are required to put SCALEUP into place (discussions and buy-in among different parties, funding, etc.); effort would be required to revert back to traditional instruction. Our lack of SCALE-UP abandoners supports this hypothesis. Although getting a SCALE-UP room is not a trivial undertaking for many secondary implementers, their efforts are rewarded in having a sustained, significant change that will be around for many years.

The implication of this is of great importance for anyone interested in sustained use of research-based instructional strategies (RBIS). The building of and use of a SCALE-UP classroom appears to be an effective reform strategy for sustainability, in addition to positive impacts on student learning. Not only does creating a classroom supports the spread of the innovation but it also encourages non-users of the classroom to integrate more RBIS in their teaching as well. We offer that if a change agent is interested in bringing about sustained change that spreads over time, creating a SCALE-UP type classroom is likely to be a worthwhile focus.

In trying to summarize how to successfully build and use a SCALE-UP classroom, we found that there is no one story, rather successful implementation happened in a variety of ways. While the stories share common themes, the adopters at each institution take different paths to implementation. The rooms deviate from the NCSU model, adapting to the instructor, the institution, and available resources. This is not a negative aspect, but rather a strength that indicates productive customization. It is important that 
the implementations maintain the intent of the classroom space: to keep an environment where students can easily collaborate.

Ultimately, having classroom space that is conducive to SCALE-UP style teaching is a huge asset to institutions that are moving toward SCALE-UP or other types of active learning teaching. The space's impact can reach beyond the SCALE-UP classroom, opening instructors to possibilities and transforming how they approach their teaching. Despite the differences among classroom space initiation, classrooms themselves, and professional development, secondary adopters retain the core ideas behind SCALE-UP and still reap benefits from the implementation. We also see SCALE-UP rooms used by institutions to symbolize their commitment to innovative teaching.

\section{Competing interests}

The authors declare that they have no competing interests.

\section{Authors' contributions}

AVK conducted some of the interviews and led the analysis of data for the article. KTF conducted some of the interviews, worked on the analysis, and provided edits. $\mathrm{CH}$ and MD conducted some of the interviews and provided feedback throughout the process. RB provided feedback throughout the process. All authors approved the final draft.

\section{Acknowledgements}

This project is supported by NSF: 1223405, 1223564, 1223405.

\section{Author details}

'Department of Physics, Western Michigan University, 1903 West Michigan Ave, Michigan 49008, USA. 'Department of Physics, University of Auckland, Auckland 1010, New Zealand. ${ }^{3}$ Department of Physics, 2000 Colorado Ave, Boulder, CO 80309-0390, USA. ${ }^{4}$ Department of Physics, North Carolina State University, 421 Riddick Hall, Campus Box 8202, Raleigh, NC 27695-8202, USA.

Received: 7 December 2015 Accepted: 25 April 2016

Published online: 05 May 2016

\section{References}

Barak, M, Lipson, A, \& Lerman, S (2006). Wireless laptops as means for promoting active learning in large lecture halls. Journal of Research on Technology in Education, 38(3), 245-263.

Beggs, TA (2000). Influences and Barriers to the Adoption of Instructional Technology. In Proceedings of the Mid-South Instructional Technology Conference. Murfreesboro: Middle Tennessee State University. (ERIC Document Reproduction Service No. ED 446 764).

Beichner, R (2008). The SCALE-UP project: a student-centered active learning environment for undergraduate programs. Invited paper for the National Academy of Sciences. Retrieved May 2, 2016 from http://publish.illinois.edu/ disruptivespaces/files/2014/07/SCALE-UP-Paper1.pdf.

Beichner, R.J (2014). History and evolution of active learning spaces: history and evolution of active learning spaces. New Directions for Teaching and Learning, 2014(137), 9-16.

Beichner, R (2015). Room design. Retrieved May 3, 2016, from https:// scaleupserver.physics.ncsu.edu/wiki/pages/42x7D5E3/Room.

Beichner, RJ, Saul, JM, Abbott, DS, Morse, J, Deardorff, D, Allain, RJ, ... \& Risley, JS (2007). The student-centered activities for large enrollment undergraduate programs (SCALE-UP) project. Research-Based Reform of University Physics, 1(1), 2-39.

Bonus, M, \& Riordan, L (1998). Increasing student on-task behavior through the use of specific seating arrangements. (Report no. PS026868). Chicago: Saint Xavier University.

Brooks, DC (2011). Space matters: the impact of formal learning environments on student learning. British Journal of Educational Technology, 42(5), 719-726.
Carnegie classifications. (2010). Retrieved May 26, 2015, from http:// carnegieclassifications.iu.edu/

Chasteen, SV, Perkins, KK, Beale, PD, Pollock, SJ, \& Wieman, CE (2011). A thoughtful approach to instruction: course transformation for the rest of us. Journal of College Science Teaching, 40(4), 70-76.

Cooke, NJ, \& Hilton, ML (Eds.). (2015). Enhancing the effectiveness of team science. Washington: National Academies Press.

Cotner, S, Loper, J, Walker, JD, \& Brooks, DC (2013). It's not you, it's the room-are the high-tech, active learning classrooms worth it? Journal of College Science Teaching, 42(6), 82-88.

Cuban, L (2001). Oversold and underused: Reforming schools through technology, 1980-2000. Cambridge: Harvard University.

Cummings, K, Marx, J, Thornton, R, \& Kuhl, D (1999). Evaluating innovation in studio physics. American Journal of Physics, 67(S1), S38-S44.

Czujko, R, Redmond, K, Sauncy, T, \& Olsen, T (2014). Equipping physics majors for the STEM workforce. College Park: AIP Statistical Research Center.

Dori, YJ, Hult, E, Breslow, L, \& Belcher, JW (2007). How much have they retained? Making unseen concepts seen in a freshman electromagnetism course at MIT. Journal of Science Education and Technology, 16(4), 299-323.

Felix, E, \& Brown, M (2011). The case for a learning space performance rating system. Journal of Learning Spaces, 1(1), 1-9.

Florman, JC (2014). TILE at lowa: adoption and adaption. New Directions for Teaching and Learning, 137, 53-59.

Foote, KT, Neumeyer, X, Henderson, C, Dancy, MH, \& Beichner, RJ (2014). Diffusion of research-based instructional strategies: the case of SCALE-UP. International Journal of STEM Education, 1(1), 1-18.

Frank, KA, Zhao, Y, \& Borman, K (2004). Social capital and the diffusion of innovations within organizations: the case of computer technology in schools. Sociology of Education, 77(2), 148-171.

Harvey, E, \& Kenyon, M (2013). Classroom seating considerations for 21 st century students and faculty. Journal of Learning Spaces, 2(1). Retrieved May 2, 2016 from http://libjournal.uncg.edu/jls/article/view/578/454.

Henderson, C, \& Dancy, MH (2007). Barriers to the use of research-based instructional strategies: the influence of both individual and situational characteristics. Physical Review Special Topics - Physics Education Research, 3(2), 1-14.

Henderson, C, \& Dancy, M (2011). Increasing the impact and diffusion of STEM education innovations. Commissioned paper for National Academy of Engineering Forum - the impact and diffusion of transformative engineering education innovations, New Orleans, LA, Feb. 7-8, 2011. Washington, DC: National Academy of Engineering.

Henderson, C, Dancy, M, \& Niewiadomska-Bugaj, M (2012). Use of research-based instructional strategies in introductory physics: where do faculty leave the innovation-decision process? Physical Review Special Topics - Physics Education Research, 8(2), 1-15.

Keiner, LE, \& Gilman, CS (2015). Implementation of interactive engagement teaching methods in a physical oceanography course. Journal of College Science Teaching, 45(2), 70-78.

Klein, KJ, \& Sorra, JS (1996). The challenge of innovation implementation. Academy of Management, 21(4), 1055-1080.

Lasry, N, Charles, E, \& Whittaker, C (2014). When teacher-centered instructors are assigned to student-centered classrooms. Physical Review Special Topics Physics Education Research, 10, 1-9.

Lippman, PC (2010). Can the physical environment have an impact on the learning environment? CELE Exchange, Centre for Effective Learning Environments, 1-6. Doi: 10.1787/20727925

Martin, SH (2002). The classroom environment and its effects on the practice of teachers. Journal of Environmental Psychology, 22, 139-156.

Narum, $J$ (2013). Student-centered active learning environment with upsidedown pedagogies (SCALE-UP). In Planning for Assessing 21st Century Spaces for 21st Century Learners (pp. 86-87).

Neumeyer, X, Foote, K., Beichner, R, Dancy, M, \& Henderson, C (2014). Examining the diffusion of research-based instructional strategies using social network analysis: a case-study of SCALE-UP. In ASEE Annual Conference and Exposition, Conference Proceedings. Washington, DC: American Society for Engineering Education

President's Council of Advisors on Science and Technology. (2010). Prepare and inspire: K-12 education in science, technology, engineering, and math (STEM) for America's future. Report to the president. Washington, DC: Executive Office of the President

Rogers, MM, Keller, LD, Crouse, A, \& Price, MF (2015). Implementing comprehensive reform of introductory physics at a primarily undergraduate 
institution: a longitudinal case study. Journal of College Science Teaching, 44(3), 82-90.

Rosenfield, P, Lambert, NM, \& Black, A (1985). Desk arrangement effects on pupil classroom behavior. Journal of Educational Psychology, 77(1), 101-108.

Samarawickrema, G, \& Stacey, E (2007). Adopting Web-Based Learning and Teaching: A case study in higher education. Distance Education, 28(3), 313-333.

Taylor, SS (2009). Effects of studio space on teaching and learning: preliminary findings from two case studies. Innovative Higher Education, 33(4), 217-228.

Walker, BJD, Brooks, DC, \& Baepler, P (2011). Pedagogy and space: empirical research on new learning environments. Educause Quaterly, 34(4), 1-24.

Wejnert, B (2002). Integrating models of diffusion of innovations: a conceptual framework. Annual Review of Sociology, 28, 297-326.

Whiteside, AL, Jorn, L, Duin, AH, \& Fitzgerald, S (2009). Using the PAIR-up model to evaluate active learning spaces. Educause Quarterly, 32(1), 1-16.

Zhu, C, \& Engels, N (2013). Organizational culture and instructional innovations in higher education: perceptions and reactions of teachers and students. Educational Management Administration \& Leadership, 42(1), 136-158.

\section{Submit your manuscript to a SpringerOpen ${ }^{\odot}$ journal and benefit from:}

- Convenient online submission

- Rigorous peer review

- Immediate publication on acceptance

- Open access: articles freely available online

- High visibility within the field

- Retaining the copyright to your article

Submit your next manuscript at $\boldsymbol{s p r i n g e r o p e n . c o m ~}$ 